NASA Contractor Report 175073

\title{
High Temperature Dispersion Strengthening of NiAl
}

(NASA-CE-175073) BIG H TEMFERATUEE DISPERSION STRENGTHENING OF NiAI Final keport (Case Hestern Eeserve Uriv.) $15 \mathrm{p}$ HC $\mathrm{AO} 2 / \mathrm{MF}$ AO 1 CSCL $11 \mathrm{~F}$

Mark Sherman and Krishna Vedula

Case Western Reserve University

Cleveland, Ohio

March 1986

Prepared for

Lewis Research Center

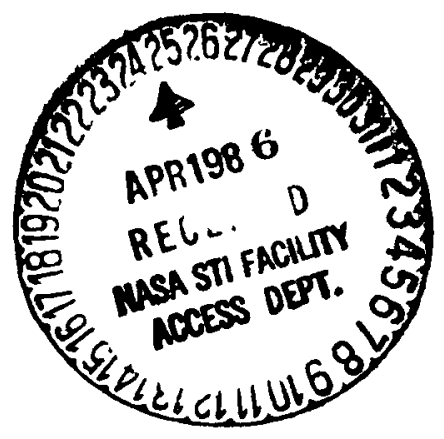

Under Grant NAG 3-387 


\title{
HIGH TEMPERATURE DISPERSION STRENGTHENING OF NIAI
}

\author{
Mark Sherman \\ Sohio Research Center, Cleveland, Ohio \\ Krishna Vedula \\ Department of Metallurgy and Materials Science, \\ Case Western Reserve University, Cleveland, Ohio
}

\section{SUMMARY}

A potential high temperature strengthening mechanism for alloys based on the intermetallic compound N1Al has been investigated. This study forms part of an overall program at NASA Lewis Research Center for exploring the potential of alloys based on NiAl for high temperature applications. An alloy containing 2.26 at $\% \mathrm{Nb}$ and produced by hot extrusion of blended powders has been examined in detall using optical and electron microscopy. Interdiffusion between the blended $\mathrm{Nb}$ and NIAl powders results in the formation of intermediate phases. A fine dispersion of precipitates of a hexagonal, ordered NiAlNb phase in a matrix of NiAl can be produced and this results in strengthening of the alloy by interfering with dislocation motion at high temperature. These precipltates are, however, found to coarsen during the high temperature $(1300 \mathrm{~K})$ deformation at slow strain rates and this may impose some limitations on the use of this strengthening mechanism.

\section{INTRODUCTION}

ordered intermetallics have long been recognized as candidates for high temperature applications because thermally actlvated processes such as diffusion are inhibited by the ordered crystal structure. Recently, interest has been generated in developing certain intermetallic compounds for high temperature applications [1-4]. The ordered intermetallic N1Al is especially attractive since this compound offers oxidation and corrosion resistance, remains ordered up to its high congruent melting point of $1913 \mathrm{~K}$, and has a density advantage over conventional superalloys because of its high aluminum content.

The drawbacks of NIAl, however, are 1ts room temperature brittleness and its inadequate creep resistance at high temperatures, in spite of its ordered crystal structure. In this paper, we are concerned only with its high temperature mechanical properties. Previous work [5] has shown that the high temperature creep resistance of N1Al can be improved to levels comparable with those of some superalloys by macroalloying with ternary additions, using a powder metallurgy process. The powder metallurgy process involves blending of elemental ternary additions with blnary NiAl followed by hot extrusion in a sealed steel contatner. Additions of $\mathrm{Nb}, \mathrm{Ta}$ and $\mathrm{Hf}$ at the 2 at\% level, in particular, have shown the most promise. The reasons for this improvement in high temperature creep resistance are, nevertheless, not clear. 
The purpose of this study was to understand the interaction between the $\mathrm{Nb}$ powder and the NiAl powder during the powder metallurgy processing of an alloy contalning 2.26 at\% $\mathrm{Nb}$ and to identify the mechanism of high temperature strengthening in this alloy. This alloy has been microscopically examined before and after high temperature deformation in order to obtain this understanding.

\section{MATERIALS AND PROCEDURE}

The alloy was prepared at NASA Lewis Research Center by blending approximately 2 at\% of -325 mesh commerclally pure Nb powder, with -80 mesh prealloyed N1Al powder. The fine $N b$ powder was used in order to enhance interdiffusion between the matrix N1Al and the ternary addition. The powder blend was filled in a mild steel can $(5 \mathrm{~cm}$. dia. and $12.5 \mathrm{~cm}$. long) which was evacuated and sealed. The sealed can was preheated to a temperature of $1366 \mathrm{~K}$ and extruded through a vertical die at an area reduction ratio of 16:1. The extruded can was alr cooled and the steel can was then removed by grinding. The alloy specimens were subsequently homogentzed at $1523 \mathrm{~K}$ in argon for 175 hours to ensure maximum interdiffusion between the ternary addition and the matrix N1Al. Spectrographic analyis of the as-homogenized alloy showed the alloy to have a nominal chemical composition of 50.19 at\% $\mathrm{Ni}, 47.58$ at\% $\mathrm{Al}$ and 2.26 at\% $\mathrm{Nb}$.

Cross-sections of the as-extruded and as-homogentzed specimens were examined using optical and scanning electron microscopy. Cylindrical specimens ( $5 \mathrm{~mm}$. dia. and $10 \mathrm{~mm}$. long) of the as-homogenized material were prepared by centreless grinding. Specimens were tested (at NASA Lewis Research Center) in compression on an Instron Testing machine at a temperature of $1300 \mathrm{~K}$ or $0.68 \mathrm{Tm}$ and at sloy strain rates. The specimen tested at an initial strain rate of $3 \times 10^{-1} / \mathrm{sec}$ to a final strain of about $7 \%$ was examined in considerable detail using optical and scanning electron microscopy .

Transmission electron microscopy of the specimens before and after compression testing was used to identify the second phases and to examine the substructure of the specimens in order to understand the strengthening mechanism. Thin folls for TEM were prepared by electropolishing in a 2:1 methanol / nitric acid solution cooled to $253 \mathrm{~K}$.

\section{RESULTS AND DISCUSSION}

\section{(A) AS-EXTRUDED AND AS-HOMOGENIZED SPECIMENS}

The as-extruded microstructure (illustrated in Figure la) contains recrystallized NiAl grains with very little porosity. The second phase particles observed are the undissolved $\mathrm{Nb}$ particles which have a wide range of sizes, the average size being roughly 4 micrometers.

The as-homogenized microstructure (1llustrated in Figure lb) shows a well developed grain structure with an average grain size of about 25 infcrometers which is somewhat larger than the as-extruded grain size. A slight increase in the amount of porosity is observed and is suspected to be 
due to pull out of particles during specimen preparation. The average size of the second phase particles has increased by about $50 \%$ to roughly 5.5

micrometers. The increase in size of the second phase particles, which were originally $\mathrm{Nb}$ powder particles, is believed to be a result of transformation of the $\mathrm{Nb}$ to a ternary intermetallic of $\mathrm{N} 1, \mathrm{Al}$ and $\mathrm{Nb}$ by interdiffusion.

The distribution of the second phase particles is clearly observed in the scanning electron micrograph in Figure 2a. Some of the larger particles reveal the presence of two phases, one surrounding the other, as 11lustrated in Figure 2b. Energy Dispersive Analysis of X-Rays from the two reglons shows that the Inner phase contains more $\mathrm{Nb}$ than the outer phase and the compositions of the phases correspond in general to the phases $\mathrm{N}_{\mathrm{AlNb}}$ and NiAlNb respectively (Figure 3 ). A more definite confirmation of the $r$ compositions could not be made since standards were not used for the analyses. These two phases are in agreement with an earlier study by Kornilov [6] on the phase equilibrlum between $\mathrm{NIAl}$ and $\mathrm{Nb}$. This $\mathrm{kind}$ of a layered structure results from incomplete interdiffusion between the matrix of NiAl and the elemental addition of $\mathrm{Nb}$.

The pseudo-binary phase diagram for NiAl-Nb is reproduced in Figure 4 from Kornilov [6]. With increasing $\mathrm{Nb}$, the phases present in this pseudo binary section are NiAl (with a very limited solubility of $\mathrm{Nb}$ ), N1AlNb and $\mathrm{N} 1 \mathrm{AlNb}{ }_{2}$. NiAl and N1A1Nb exhibit a eutectic at about $1710 \mathrm{~K}$. The solubility of $\mathrm{Nb}$ In NiAl, according to this diagram is less than 1 at\% at low temperatures, but increases significantly above about $1450 \mathrm{~K}$ and can approach 5 at\% near the eutectic temperature. Hence, during the homogenization treatment $(1523 \mathrm{~K})$, the matrix of $\mathrm{NiAl}$ and the $\mathrm{Nb}$ powder particles act as a finite spherical diffusion couple and the phases corresponding to the two intermediate ternary intermetallics form between the NiAl and the $\mathrm{Nb}$.

Since the solubility of $\mathrm{Nb}$ in NiAl is much higher at the homogenization temperature than at room temperature, the slow cooling after the homogenization treatment results in reprecipitation of a second phase of NiAlNb in the matrix of NiAl. A distribution of very fine precipitates is, in fact, observed when a thin foll is examined on the Transmission Electron Microscope at a high magnification (Figure 5a). These precipitates are, however, only 10 to $50 \mathrm{~nm}$. In slze and too small to be detected at the low magnifications used in the optical and scanning electron micrographs. A diffraction pattern showing the spots for the matrix as well as the precipitates is shown in Figure 5b. The diffraction spot used to obtain the dark fleld image of the preclpitates in Figure $5 \mathrm{a}$ is indicated by the arrow in Figure $5 b$.

\section{(B) DEFORMED SPECIMEN}

Cylindrical specimens were tested at slow strain rates in compregsion and the behavior of a specimen with an initial strain rate of $3 \times 10^{-7} / \mathrm{sec}$ is plotted in the form of a true stress- true plastic strain curve in Figure 6 and compared with similar curves for binary NiAl*. Plastic flow in the ternary alloy is initlated at a stress of about $35.0 \mathrm{MPa}$ which is significantly higher than that for the binary alloy, Indicating a substantial strengthening due to the ternary addition. The flow stress, however, drops

*Unpublished results from J.D. Whittenberger of NASA Lewis Research Center. 
during the deformation to a lower value of about $29 \mathrm{MPa}$ after a plastic strain of about 4\%. A possible explanation for the strengthening can be obtained from an understanding of the microstructure of the tested specimen.

The matrix NiAl grains appear to have grown somewhat during the testing as evidenced by comparing the optical microstructure of the tested specimen in Figure $7 \mathrm{a}$ with that of the untested specimen in Figure $1 \mathrm{~b}$. The average grain size measured shows an increase from about 25 micrometers to about 33 micrometers. A considerable amount of etch pitting within the grains is suspected to be assoclated with dislocations within these grains. Voids appear to have coalesced along the triple points and grain boundaries during the testing, presumably due to grain boundary sliding.

A striking feature of the deformed specimen when compared with the undeformed specimen 18 the presence of many precipitates within the grains of the deformed specimen when compared on the scanning electron microscope in the backscatter mode (F1gure 7b compared w1th Figure 2a). These precipitates are between 0.5 to 1 micrometer in size and much smaller than the original $\mathrm{Nb}$ powder particles. These precipitates have been shown to be NiAlNb precipitates and could be a result of coarsening of much finer precipitates which were not resolved on the SEM in the homogentzed specimen.

An interesting aspect of the microstructure of the deformed specimen is the presence of reglons around the large particles which are devold of the fine precipitates. Such a precipitate-free zone must be a consequence of dissolution of smaller prectpates in the vicinity of the larger particles and redeposition on the surface of the larger particles due to Ostwald ripening.

Transmission electron microscopy of the deformed specimen reveals precipitates of the size of about $500 \mathrm{~nm}$ (Figure 8 ), thus, providing direct evidence that the precipitates have coarsened significantly during the high temperature testing (compare Figure 5 with Figure 8 ). The size of the precipitates observed in the transmission electron micrograph is in agreement w1th the size observed in the scanning electron micrograph of the tested specimen. A possible reason for the rapid coarsening during deformation may be increased diffusion through dislocation pipes.

\section{(C) STRENGTHENING MECHANISM}

The mechanism of strengthening in the ternary alloy is believed to be due to the interaction between the fine preclpitates and dislocations. Dislocation bowing as well as development of dislocation networks between the precipitates are observed throughout the thin foll of the deformed specimen. Typical examples are illustrated in Figures $9 \mathrm{a}$ and $9 \mathrm{~b}$. This kind of interaction is generally observed when the precipitates act as obstacles to dislocation motion and hence strengthen the material $[9,8,9]$.

Dislocation networks with segments parallel to $\langle 101\rangle$ and $\langle 110\rangle$ g vectors developed between preclpitate particles. Curved dislocation ines are dominant at and near precipitates, whereas straight parallel dislocations were observed in groups in the matrix and piled up at elongated particles. Subgrain boundaries were observed at grain boundarles and at the 
precipitates. The burgers vectors of dislocations in the deformed specimen were not uniquely determined. However, in general, the dislocations were strongly visible with (110) reflections and invisible with (112) reflections.

The identification of the precipitates which are believed to cause the strengthening was carrled out using selected area and microdiffraction on the transmission electron microscope using the deformed specimen. The precipitates in the undeformed specimen were too small to be properly analyzed and it is assumed that they have the same composition and crystal structure as those identified in the tested specimen. The precipitates in the deformed specimen are found to be NiAlNb with a hexagonal crystal structure. A TEM bright field image of one of the precipitates and the corresponding SAD and microdiffraction patterns of a zone axis are shown in Figure 10. Measurements from several diffraction patterns conflem the hexagonal phase NiAlNb. The d-spacings from the Inorganic Powder Diffraction File for NiAlNb and those measured from electron diffraction patterns are presented in Table 1. X-Ray diffraction of the deformed specimen in a powder form, also agreed with the conclusion that the second phase present in the matrix of N1Al is the hexagonal phase N1A1Nb. These data are also presented in the same table for comparison. The possibility of the second phase being $\mathrm{NI}_{2} \mathrm{~A} 1 \mathrm{Nb}$ ( $\mathrm{a}$ Heusler alloy) was very carefully checked and ruled out.

In terms of the strengthening mechanism in the ternary alloy, since the ternary intermetallic phase NiAlNb is harder than the binary NiAl [6], dislocation motion at the testing temperature appears to be hindered by the presence of these fine precipitates. Such a mechanisin is very sensitive to the average spacing between and hence the slze of the precipitates for a given volume fraction. Coarsening of these precipltates could, therefore, have dramatic consequences for strengthening. In fact, the drop of flow stress during the test is suspected to have been caused by coarsening of the precipitates from about $50 \mathrm{~nm}$ observed in the undeformed as-homogenized specimen to about $500 \mathrm{~nm}$ in the deformed specimen. At the same time, the dislocations present between the preclpitates may act as rapid paths for diffusion in the matrix, thereby enhancing the kinetics of the coarsening of the precipitates.

It should be pointed out here that these results are in agreement with the proposed strengthening mechanism in an alloy containing 2 at\% Ta [10], investigated as part of the same overall program for investigating the effect of ternary additions on N1Al at NASA Lewls Research Center.

\section{CONCLUSIONS}

The results of this investigation suggest the following conclustons:

1) Homogenization of ternary alloys of $\mathrm{N1Al}$ and $\mathrm{Nb}$, prepared by hot extrusion of powder blends of $\mathrm{NiAl}$ and $\mathrm{Nb}$, results in the formation of the intermediate phases $\mathrm{N} 1 \mathrm{~A} 1 \mathrm{Nb}$ and $\mathrm{N}^{\prime A 1 N b}{ }_{2}$.

2) The high temperature strengthening of this alloy appears to be due to a dispersion of fine precipitates ( $-50 \mathrm{~nm}$ in size) of NiAlNb which have a hexagonal crystal structure. These precipitates interfere with dislocation 
motion during high temperature deformation.

3) The strengthening precipitates coarsen significantly during the testing (from about $50 \mathrm{~nm}$ to $500 \mathrm{~nm}$ ) and this coarsening may be responstble for the drop in flow stress during the deformation.

\section{ACKNOWLEDGEMENTS}

The authors would like to acknowledge the support of Sohlo Research Center for the use of their microscopy facilities and NASA Lewis Research Center for supplying the materials. 


\section{REFERENCES}

1. "Structural Uses for Ductile Ordered Alloys", NMAB Report No. 419, August 31, 1984, National Research Council, Washington, D.C.

2. J.R. Stephens, "The B2 Aluminides as Alternative Materials", NASA Technical Memorandum 86937, prepared for the 1984 Fall Meeting of the Materials Research Soclety, Boston, Nov., 1984 .

3. N.S. Stoloff, Internatlonal Metals Revlews, 1984, Vol. 29. No. $3, \mathrm{p} .123$.

4. C.T. Liu, 'Design of Ordered Intermetallic Alloys for High Temperature Structural Uses'. Paper presented at the AIME Symposium on High Temperature Alloys, Theory and Design, Apri1 1984, Bethesda, Maryland.

5. K.M. Vedula, V. Pathare, I. Aslanidis and R.H. Titran, to be published in the Proceedings of a Symposium on High Temperature Ordered Intermetallic Alloys at the Materials Research Soclety Meeting, Boston, November, 1984.

6. I.I. Kornilov, R.S. Mints, L.N. Guseva, Yu.S. Malkov, Russian Metallurgy, No.6, 1965, p.83.

7. O.D. Sherby, R.H. Klundt and A.K. Miller, Met. Trans. 1977, Vol. $8 \mathrm{~A}, \mathrm{p} .843$.

8. G.S. Ansel.1 and J. Weertman, Trans. AIME, 1959, Vol. 215, p.838.

9. J.J. Petrovlc and L.J. Ebert, Met. Trans. Vol. 4, 1973, p.1309.

10. V.M. Pathare, M.S. Thes1s, Department of Metallurgy and Materials Sclence, Case Western Reserve University, Cleveland, Ohio, 1984. 
TABLE 1: COMPARISON OF d-VALUES FROM POWDER DIFFRACTION (PD) FILE FOR NIAINb WITH THOSE DETERMINED BY ELECTRON DIFFRACTION (ED) FROM PRECIPITATES AND X-RAY DIFFRACTION (XRD) OF PULVERIZED HOMOGENIZED ALLOY IN THIS STUDY.

Hexagonal $12 \mathrm{H} \quad \mathrm{a}=5.00 \quad \mathrm{c}=8.093$

\begin{tabular}{llll}
\hline & \multicolumn{3}{c}{ ANGSTROMS } \\
Mk1 & PD FILE & MEASURED, ED & \\
\hline 100 & 4.33 & 4.35 & \\
002 & 4.05 & 4.06 & \\
101 & 3.82 & 3.83 & \\
102 & 2.96 & 2.96 & 2.10 \\
201 & 2.09 & 2.11 & 2.47 \\
110 & 2.50 & & 1.26 \\
103 & 2.29 & 2.25 & 1.23 \\
213 & 1.39 & & \\
220 & 1.25 & & \\
\hline
\end{tabular}




\section{ORIGINAL PAGE IS OF POOR QUALTY}

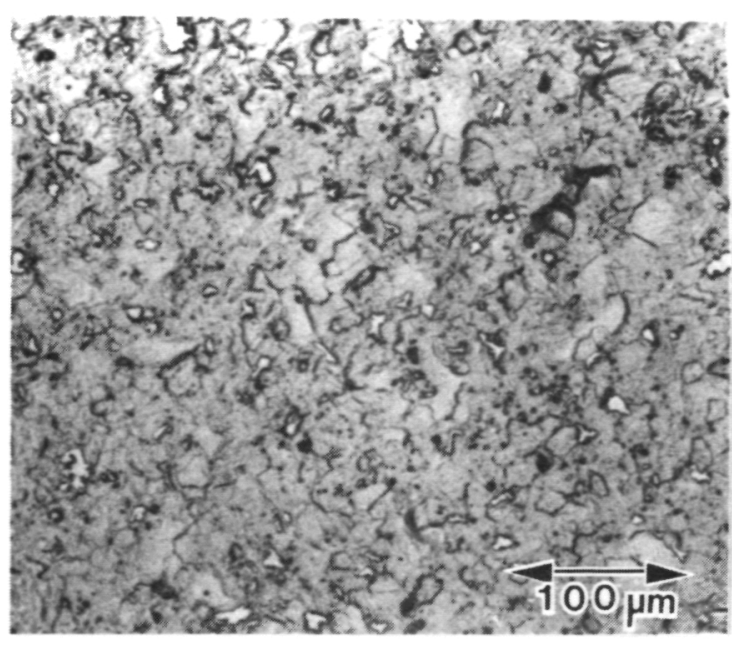

(a)

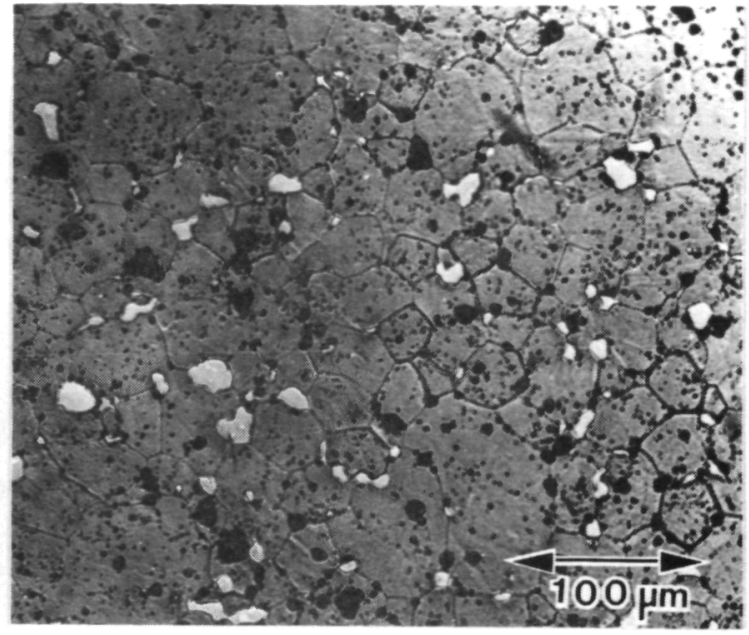

(b)

Figure 1. Comparison of Optical Micrographs of Cross-sections of (a) As-Extruded and (b) As-Homogenized specimens of the NiA1-2.26 at\% Nb alloy (Marbles Reagen Etch)

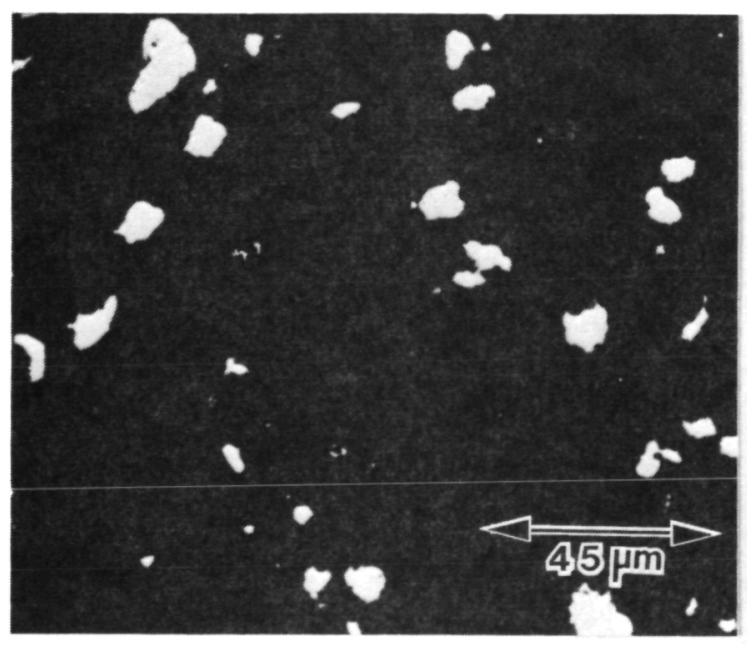

(a)

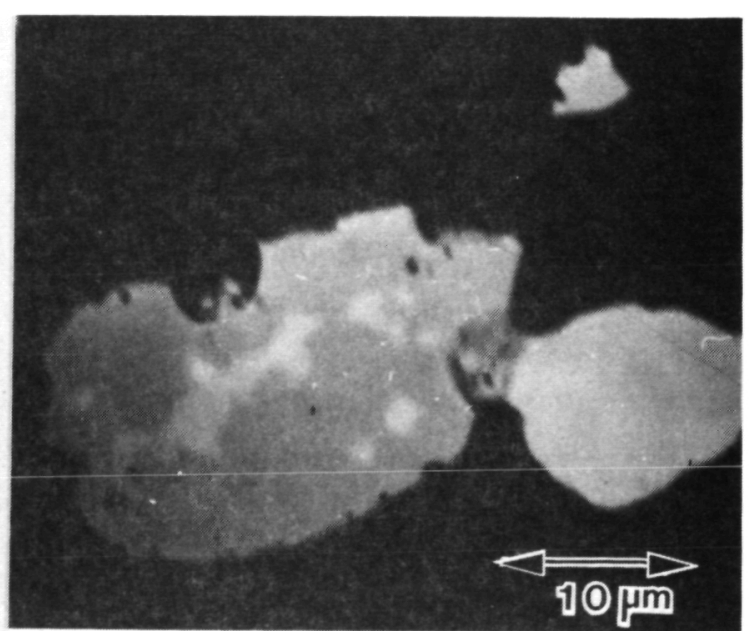

(b)

Figure 2. SEM Backscattered Electron Images of the Homogenized Alloy Showing (a) A Typical Distribution of Nb-rich Particles and (b) The Existence of a Layered Two Phase Structure within some of the Larger Particles. (Cross-section). 


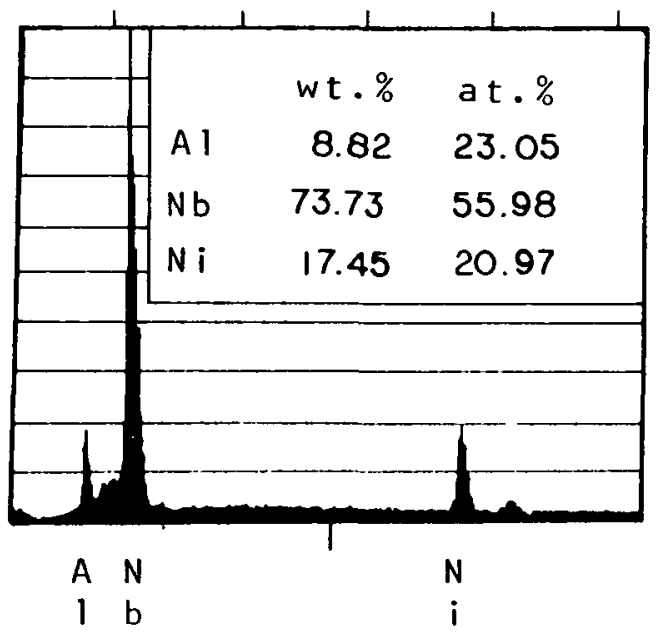

(a)

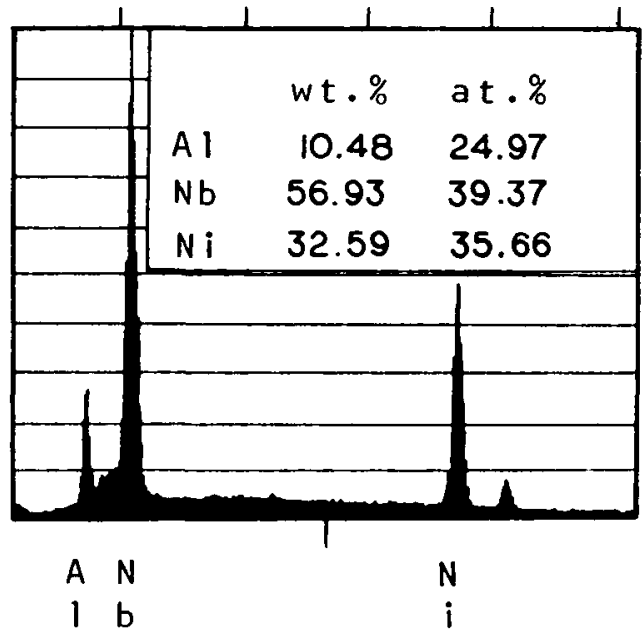

(b)

Figure 3. EDS Analysis of the Two Regions of Particle in Figure 2b (a) The Inner Phase Corresponding Roughly to $\mathrm{NiAlNb}_{2}$ and (b) The Outer Phase Corresponding Roughly to NiAlNb.

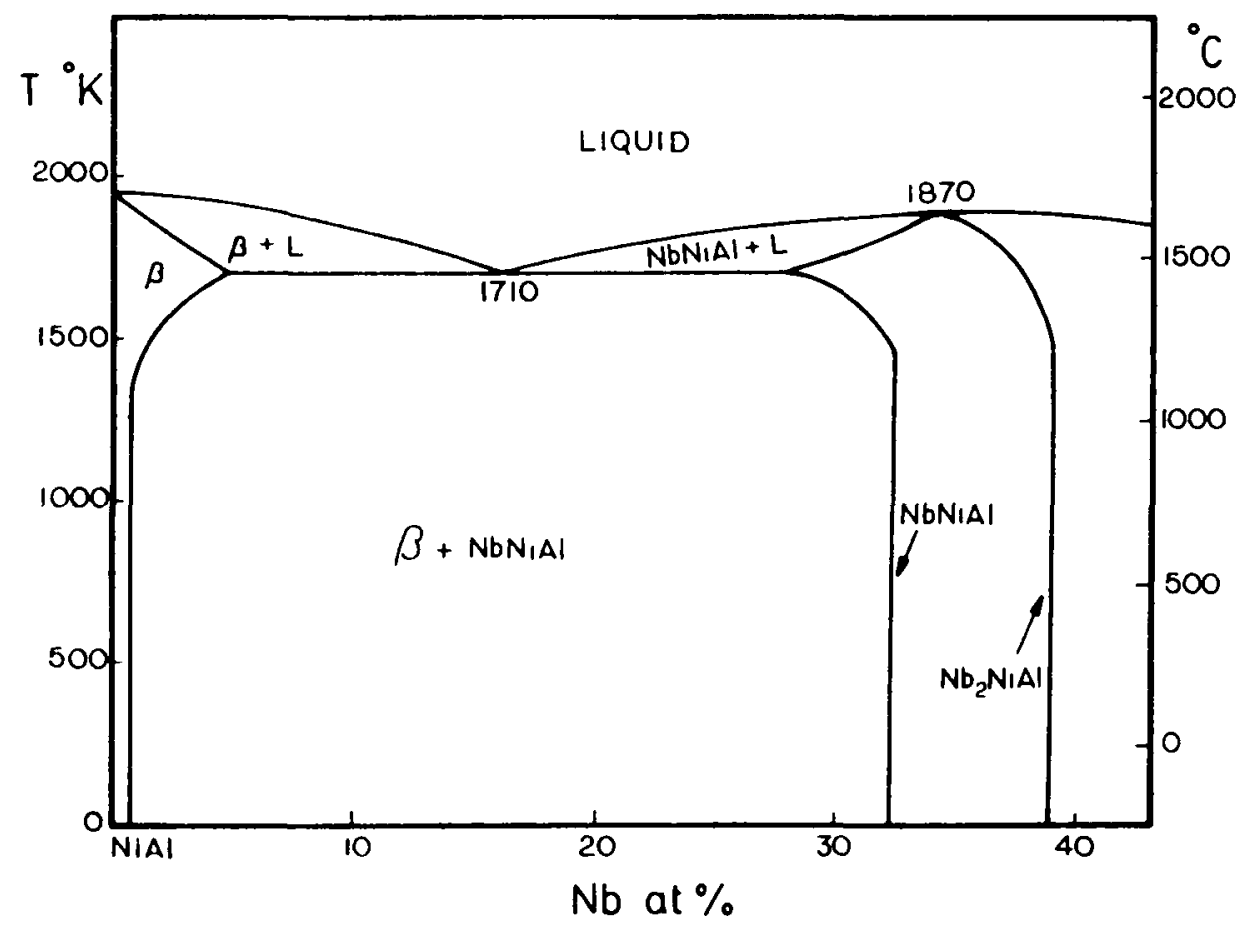

Figure 4. Pseudo-Binary Phase Diagram of the NiAl-Nb system. (Kornilov, Ref. 6). 


\section{ORIGINAL PAGE IS \\ OF POOR QUALTY}

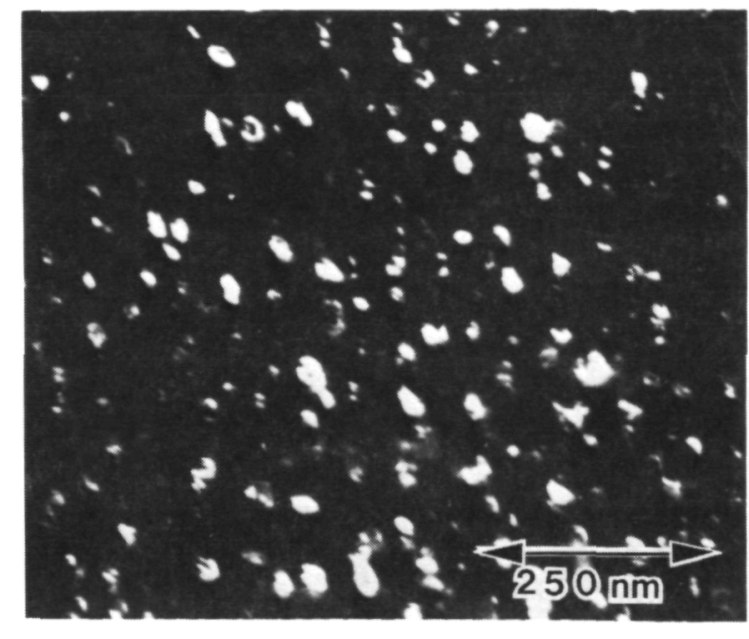

(a)

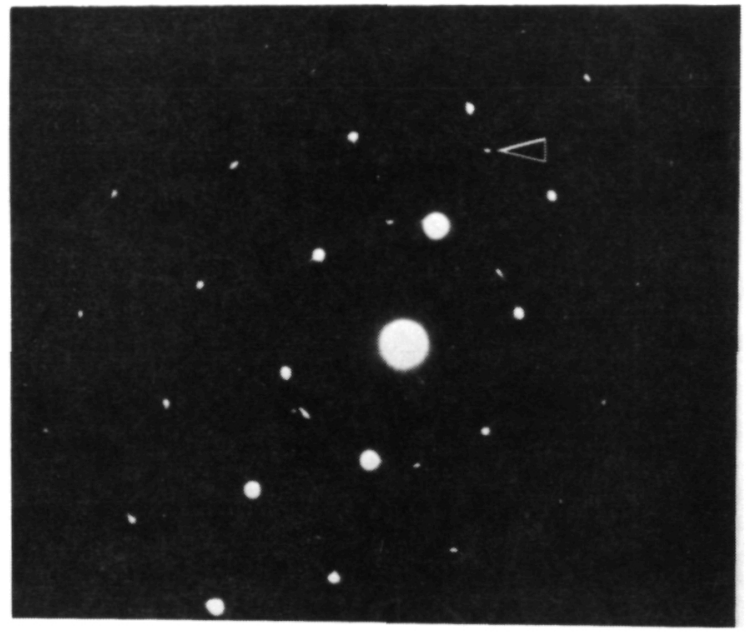

(b)

Figure 5. (a) TEM Dark Field Image of Precipitates in the Homogenized Alloy and (b) The Corresponding Diffraction Pattern with Arrow Indicating the Reflection used for Imaging .

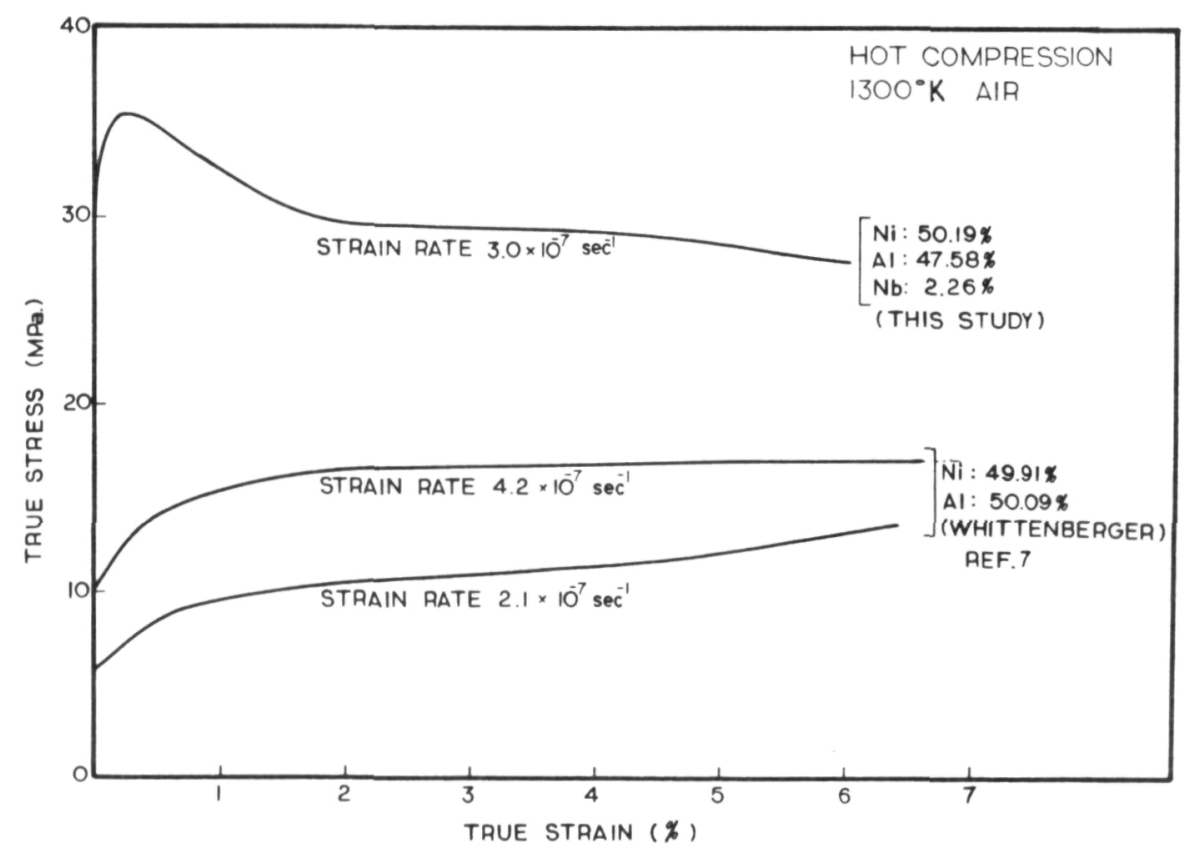

Figure 6. Comparison of the True Stress- True Plastic Strain Behavior of the $\mathrm{Nb}$ Containing Alloy with a Binary NiAl Alloy (Ref. 7). Specimens Tested in Compression at $1300 \mathrm{~K}$ and Slow strain Rates. 


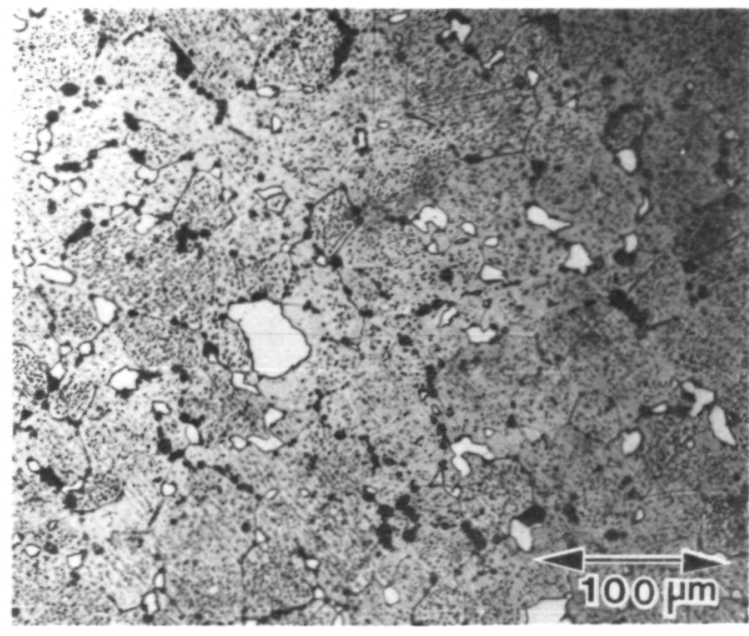

(a)

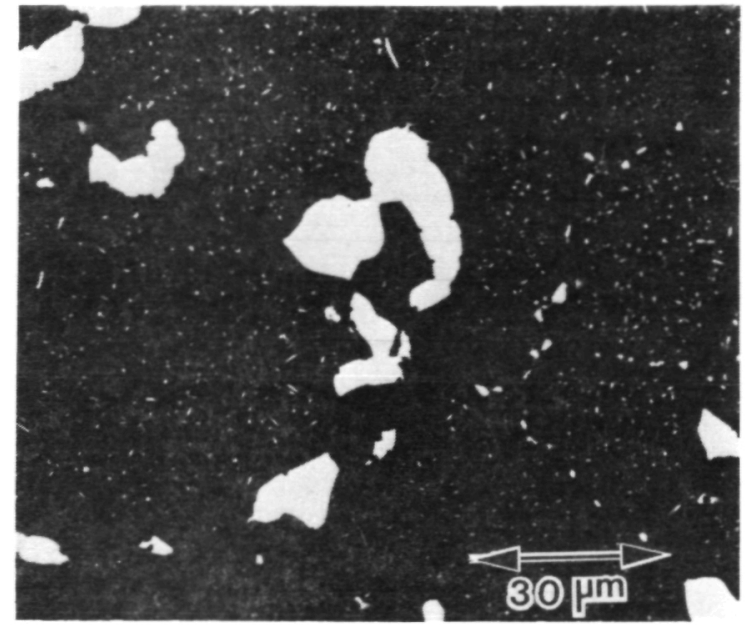

(b)

Figure 7. (a) Optical Microstructure of Specimen after Testing Showing Grain Boundary Void Formation (Etched), (b) SEM Backscattered Electron Image of Same Specimen Showing Coarsened NiAlNb Precipitates and Precipitate Depleted Regions Around Original Nb-Rich Particles.

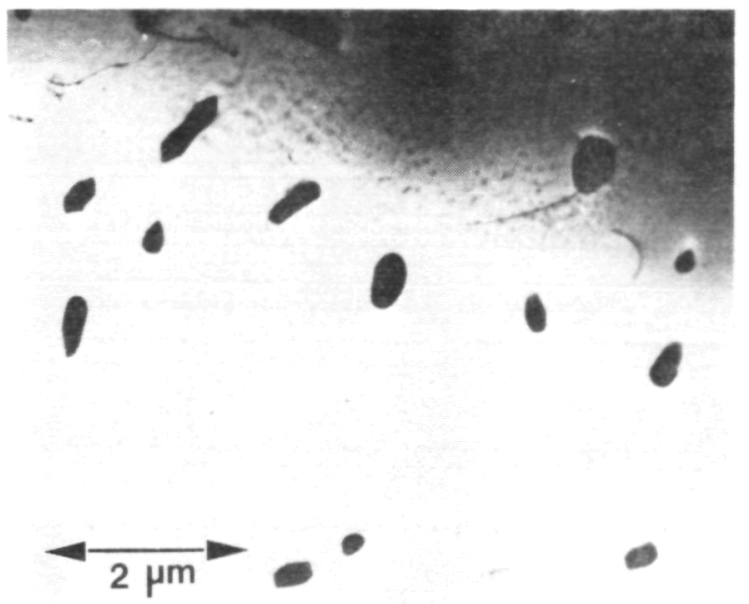

Figure 8. TEM Bright Field Image of Deformed Specimen Showing Coarsened Precipitates of NiAlNb. 


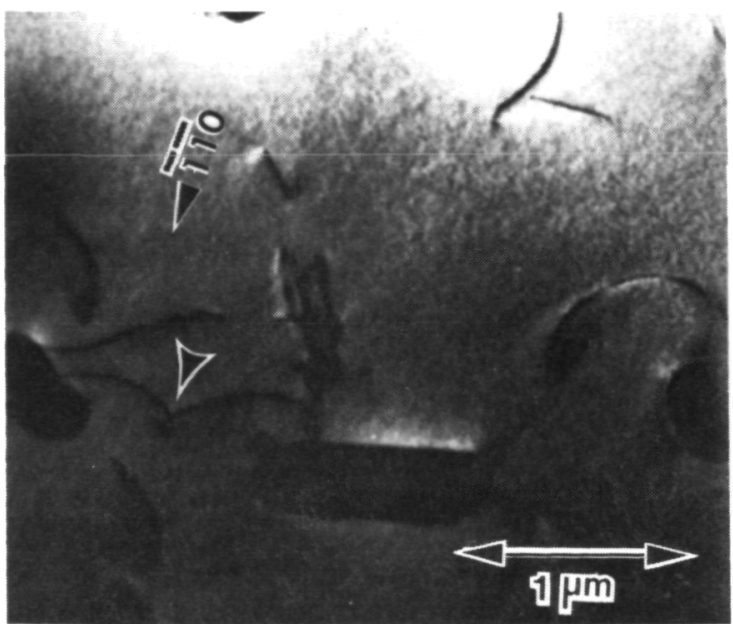

(a)
ORIGINAL PAGE IS OF POOR QUALTTY

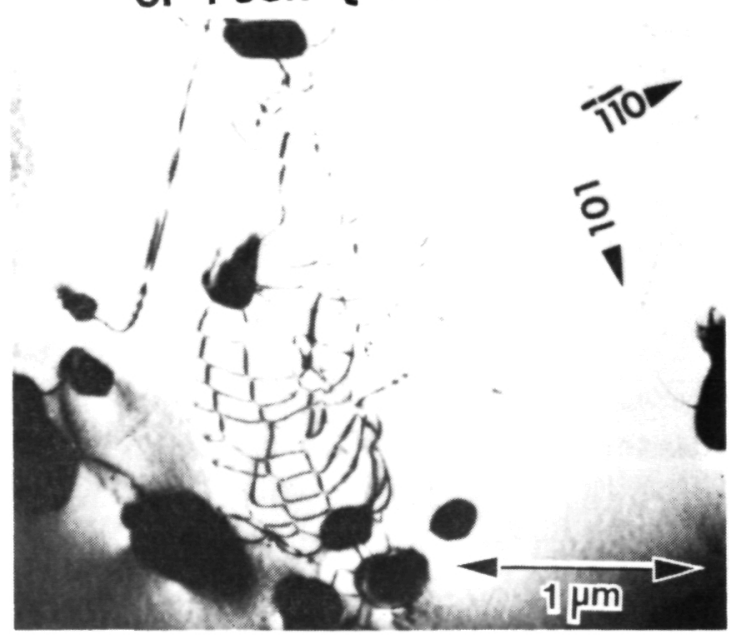

(b)

Figure 9. Transmission Electron Micrographs of Deformed Specimen Illustrating (a) Dislocations Pinned at and bowing Between Precipitates and (b) Dislocation Networks Formed Between Precipitates.
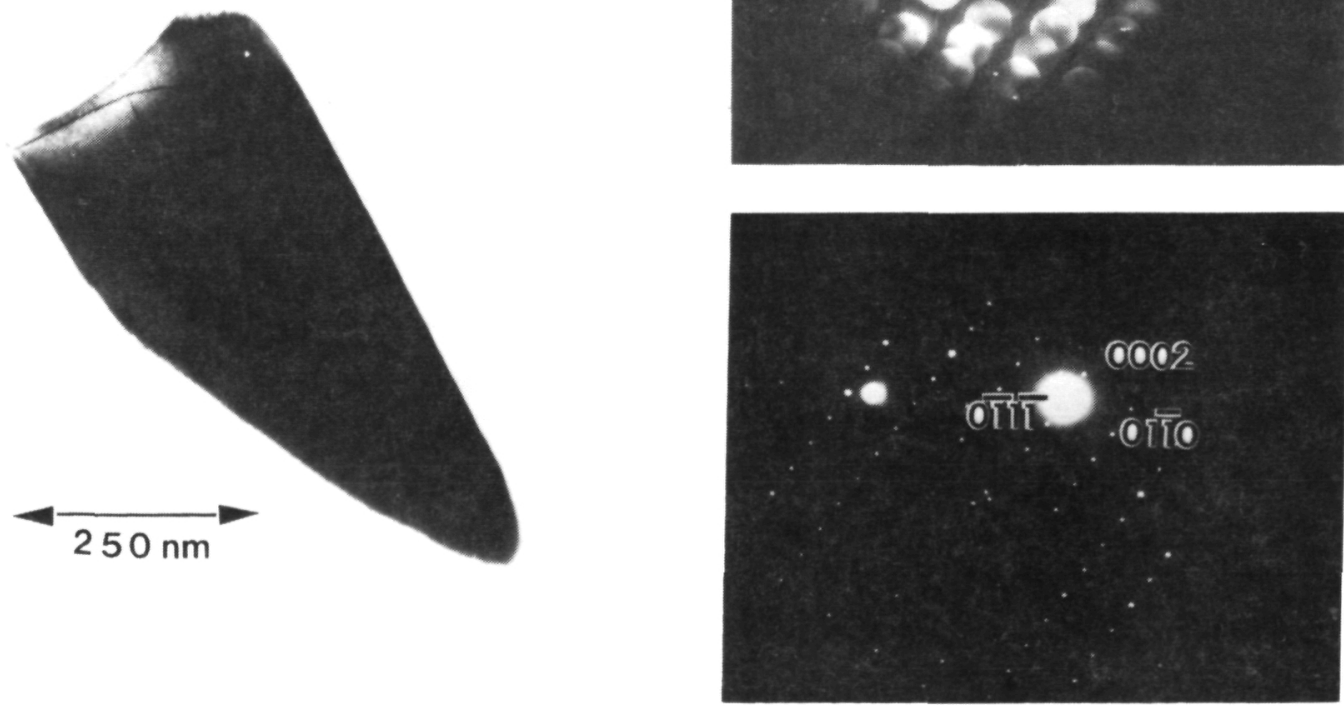

Figure 10. TEM Bright Field Image of a Large Precipitate in the Deformed Specimen and Corresponding SAD and Microdiffraction Patterns of a Zone Axis Indexed as (2īio). 


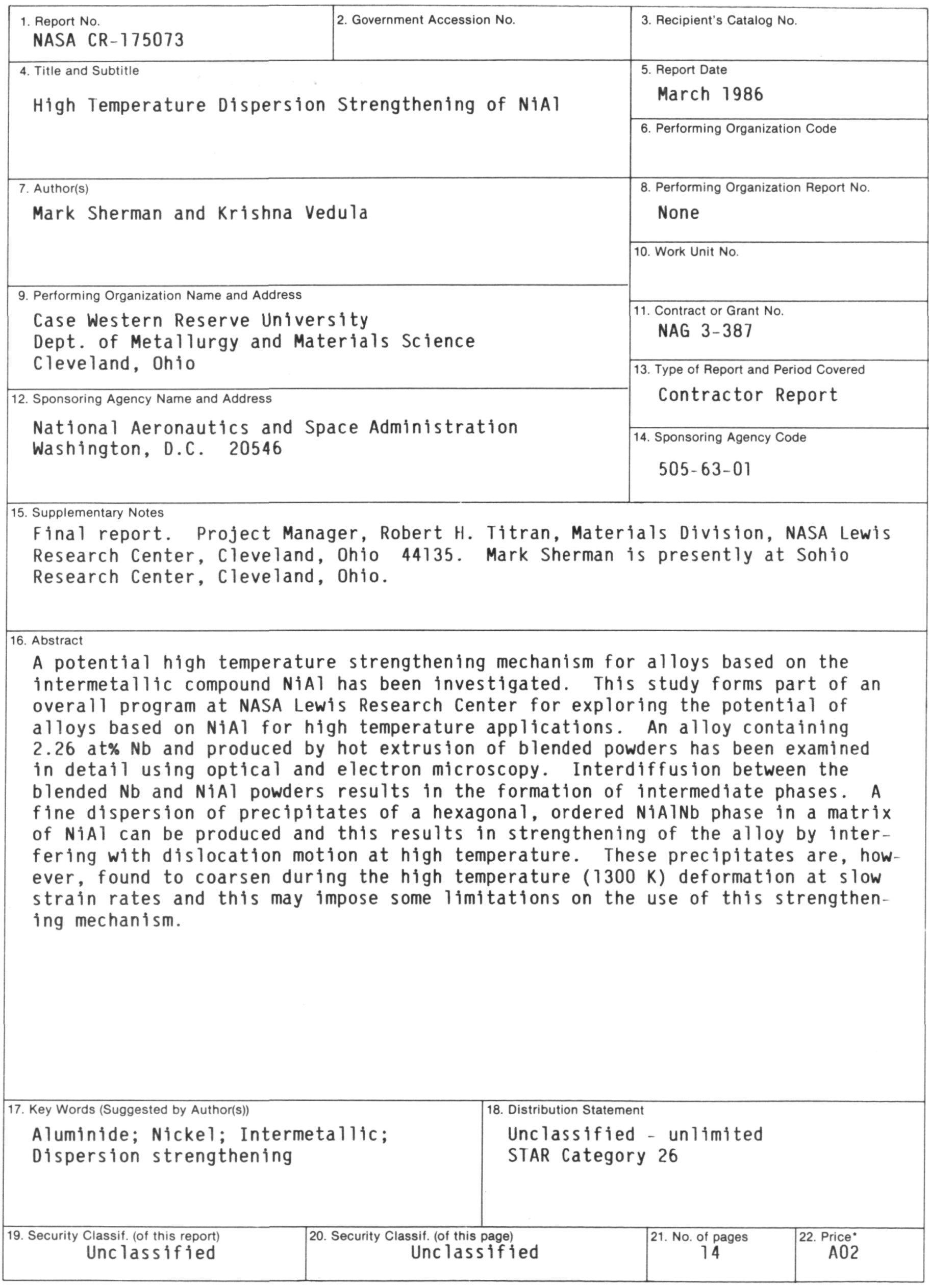

*For sale by the National Technical Information Service, Springfield, Virginia 22161 
National Aeronautics and

Space Administration

Lewis Research Center

Cleveland. Ohio 44135

Orincid Businees

Penally for Pitvato Uso $\$ 200$
SECOND CLASS MAIL

ADDRESS CORRECTION REQUESTED National Aeronautics and Space Administration NASA-451 